\title{
INFLUÊNCIA DA DENSIDADE DE PLANTIO E SISTEMA DE PODAS NA PRODUÇÃO DE CAFÉ ${ }^{1}$
}

\author{
SÉRGIO VASCO DE TOLEDO² e INÁCIO DE BARROS ${ }^{3}$
}

\begin{abstract}
RESUMO - Durante 19 anos, foi conduzido um experimento em Campinas, SP, que objetivou avaliar a influência da variedade, espaçamento, número de plantas na cova e sistema de condução da planta sobre a produção de café (Coffea arabica L.). As variedades Mundo Novo e Caturra foram estudadas com cinco densidades de plantio $\left(1,2,3,5\right.$ e $6 \mathrm{~m}^{2} /$ cova) combinadas com uma ou duas plantas por cova e conduzidas sem podas, decotadas a $2 \mathrm{~m}$ de altura e recepadas em esquema predeterminado, tipo Beaumont \& Fukunaga. Os resultados de 17 colheitas demonstraram que altas densidades de plantio apresentaram elevadas produções nas primeiras safras, com acentuado decréscimo após sete colheitas; a variedade Mundo Novo manteve o potencial produtivo, enquanto a Caturra diminuiu sensivelmente a produção ao longo dos anos; a adoção de um sistema de podas não influenciou na produção, e em alguns períodos foi prejudicial.
\end{abstract}

Termos para indexação: Coffea arabica, variedades, espaçamento, poda.

\section{INFLUENCE OF PLANT DENSITY AND PRUNING SYSTEM ON THE YIELD OF COFFEE}

\begin{abstract}
An experiment with the objective of evaluating the influence of the number of plants per hole, plant density and pruning system on the yield of the Caturra and Mundo Novo varieties of Coffea arabica L. was carried out in Campinas, SP, Brazil, during 19 years. Five planting densities were evaluated: 1, 2, 3, 5 and $6 \mathrm{~m}^{2} /$ hole, combined with one and two plants per hole carried out without pruning; pruning at $2 \mathrm{~m}$ from the soil; and, plants lapped close to the soil in a regime pre-determinated by Beaumont \& Fukunaga. High planting density showed high yields in the first harvests with pronounced decrease after seven harvests. The Mundo Novo variety kept its yield potential while the Caturra variety highly decreased its yield throughout the years; the adoption of a pruning system did not influence the yield and was even prejudicial in some periods.
\end{abstract}

Index terms: Coffea arabica, varieties, plant density.

\section{INTRODUÇÃO}

O aumento na população de plantas acarreta um acréscimo na produção de café por unidade de área nas primeiras safras, conforme Leon \& Umaña (1959), Scaranari \& Nogueira Neto (1963), Peres (1977), Viana et al. (1978) e Siqueira et al. (1985). Todavia, a densidade ideal para máxima produção apresenta valores bastante diferenciados de acordo com a

${ }^{1}$ Aceito para publicação em 15 de junho de 1998.

${ }^{2}$ Eng. Agr., Seção de Café, Instituto Agronômico (IAC), Caixa Postal 28, CEP 13001-970 Campinas, SP.

${ }^{3}$ Eng. Agr., M.Sc., Seção de Genética, IAC. E-mail: inacio@cec.iac.br região. Na Colombia, Henao\& Mestre (1988a) obtiveram maior produção na densidade de 14.740 plantas/ha; já Scaranari \& Nogueira Neto (1963) no Brasil, e Mitchell (1976) no Kenya, observaram ser de 5.000 covas/ha a densidade mais produtiva. Por outro lado, Bellavita (1968), na Venezuela, e Rodriguez et al. (1966), em Porto Rico, concluíram que as melhores densidades são de 6.666 e 6.000 plantas/ha, respectivamente, enquanto Hangdong \& Bartolome $(1963,1966)$ apontaram a população de 3.333 covas/ha como a mais adequada.

No caso da lavoura de café, o número de plantas em determinada área depende do espaçamento entre covas e do número de plantas por cova; Henao 
\& Mestre (1988b) obtiveram as melhores produções com uma população de 10.000 plantas/ha com a utilização de 1, 2 ou 3 plantas/cova, em espaçamentos diferenciados.

Com o crescimento das plantas ao longo dos anos, há um fechamento da lavoura com alta densidade de plantio, dificultando os tratos culturais, diminuindo a produção por causa da concorrência entre os cafeeiros (Viana et al., 1978), e por incrementar a infestação de fungos causadores de doenças como a ferrugem e a "Coffee Berry Disease" (CBD) (Mitchell, 1976). A alta densidade de plantio provoca também a perda dos ramos produtivos da base da planta, em decorrência da baixa insolação, o que acarreta queda na produtividade.

Entretanto, alguns benefícios são trazidos com o uso de elevadas densidades de plantio, tais como: a diminuição da infestação por bicho-mineiro (Perileucoptera cofeela); a menor necessidade de controle de ervas invasoras; o aumento no rendimento de operações de fertilização; a diminuição da erosão, por manter maior área de solo coberto, e a utilização mais eficiente dos fertilizantes aplicados (Hangdong, 1966; Pavan et al., 1994).

Para contornar os problemas adversos causados pelo fechamento do cafezal, é necessário a adoção de alguma técnica de manejo da lavoura por meio de podas ou da eliminação de ruas (Oliveira et al., 1990). Toledo et al. (1994) apontam a recepa total como o sistema mais adequado para lavouras de Acaiá com densidade de 5.000 a 10.000 plantas/ha, ou então, a eliminação de metade das ruas após a terceira safra.

O presente trabalho teve como objetivo avaliar a influência da variedade, espaçamento, número de plantas na cova e sistema de condução da planta sobre a produção de café.

\section{MATERIAL E MÉTODOS}

O experimento foi instalado no centro experimental do Instituto Agronômico (IAC) em Campinas, Estado de São Paulo, em área de Latossolo Roxo, com as variedades de café Caturra Amarelo e Mundo Novo IAC LMP-376-4. Foram estudadas 5 densidades de plantio, duas quantidades de mudas por cova e três tipos de condução da planta (sem poda; com decote a $2 \mathrm{~m}$ de altura, e recepa por linha no esquema Beaumont \& Fukunaga).

O delineamento experimental foi o de blocos ao acaso, com quatro repetições. Utilizaram-se parcelas com dimensões de 84, 112, 150 e $120 \mathrm{~m}^{2}$, para as densidades de $1,2,3,5$ e $6 \mathrm{~m}^{2} /$ cova, respectivamente. Os tratamentos estão apresentados na Tabela 1.

A recepa foi realizada de acordo com o sistema de podas proposto por Beaumont \& Fukunaga (1958), em que se faz a recepa baixa de $20 \%$ da área a cada ano, em esquema fixo para cada grupo de cinco ruas, sendo podadas, anualmente, em sequiência, as ruas $2,4,1,3,5$ e conduzidas com três brotos por tronco.

A poda tipo decote foi aplicada a $2 \mathrm{~m}$ de altura da planta, após a sétima colheita, e conduzida com desbrotas anuais nos meses de setembro e fevereiro, a fim de manter a altura das plantas, sendo, portanto, eliminadas todas as brotações.

As parcelas apresentavam bordadura simples, e receberam a adubação no sulco de plantio nas quantidades de $60 \mathrm{~kg} / \mathrm{ha}$ de $\mathrm{P}_{2} \mathrm{O}_{5}$ e $60 \mathrm{~kg} / \mathrm{ha}$ de $\mathrm{K}_{2} \mathrm{O}$, na forma de superfosfato simples e cloreto de potássio, respectivamente. Após o pegamento das mudas, foram aplicados em cobertura, a cada 45 dias, de janeiro a abril, $8 \mathrm{~g} /$ cova de $\mathrm{N}$, tendo como fontes o nitrocálcio e o sulfato de amônio alternadamente. No segundo ano, os cafeeiros receberam $54 \mathrm{~g} /$ cova de $\mathrm{Ne} 24 \mathrm{~g} /$ cova de $\mathrm{K}_{2} \mathrm{O}$, divididas em quatro aplicações. No terceiro ano, foram aplicados $108 \mathrm{~g} /$ cova de $\mathrm{N}, 20 \mathrm{~g} /$ cova de $\mathrm{P}_{2} \mathrm{O}_{5}$ e

TABELA 1. Relação dos tratamentos.

\begin{tabular}{|c|c|c|c|c|c|}
\hline Tratamentos & Variedade & Espaçamento (m) & $\begin{array}{c}\text { Densidade } \\
\left(\mathrm{m}^{2} / \text { cova }\right)\end{array}$ & Planta/cova & $\begin{array}{l}\text { Sistema } \\
\text { de poda }\end{array}$ \\
\hline 1 & Caturra & $1,62 \times 0,62$ & 1 & 1 & Recepado \\
\hline 2 & Caturra & $2,00 \times 1,00$ & 2 & 1 & Recepado \\
\hline 3 & Caturra & $2,30 \times 1,30$ & 3 & 1 & Recepado \\
\hline 4 & Caturra & $1,62 \times 0,62$ & 1 & 2 & Recepado \\
\hline 5 & Caturra & $2,00 \times 1,00$ & 2 & 2 & Recepado \\
\hline 6 & Caturra & $2,30 \times 1,30$ & 3 & 2 & Recepado \\
\hline 7 & Caturra & $2,79 \times 1,79$ & 5 & 2 & Sem podas \\
\hline 8 & Mundo Novo & $2,30 \times 1,30$ & 3 & 2 & Recepado \\
\hline 9 & Mundo Novo & $3,00 \times 2,00$ & 6 & 2 & Decotado \\
\hline 10 & Mundo Novo & $3,00 \times 2,00$ & 6 & 2 & Sem podas \\
\hline
\end{tabular}


$60 \mathrm{~g} /$ cova de $\mathrm{K}_{2} \mathrm{O}$, divididos em quatro aplicações. A partir do quarto ano agrícola (adubação de produção), os cafeeiros passaram a receber anualmente $380 \mathrm{~kg} / \mathrm{ha}$ de $\mathrm{N} ; 80 \mathrm{~kg} / \mathrm{ha}$ de $\mathrm{P}_{2} \mathrm{O}_{5}$ e $240 \mathrm{~kg} / \mathrm{ha}$ de $\mathrm{K}_{2} \mathrm{O}$, divididos em quatro aplicações durante o período de outubro a abril. $\mathrm{O} \mathrm{N}$ foi fornecido nas formas de nitrocálcio e sulfato de amônio, aplicados alternadamente.

Os micronutrientes $\mathrm{B}$ e $\mathrm{Zn}$ foram fornecidos por meio de pulverizações com $6 \mathrm{~g} / \mathrm{L}$ de sulfato de zinco, nos meses de novembro e fevereiro, e de aplicações de bórax na superfície do solo, nas quantidades de $10 \mathrm{~g} /$ cova, no segundo ano agrícola, e $20 \mathrm{~g} /$ cova nos anos subseqüentes.

A primeira safra ocorreu no segundo ano após o plantio. As podas, em esquema Beaumont \& Fukunaga, começaram a ser adotadas logo após a segunda safra, e o decote, após a sétima colheita. Foram medidas as produções, em kg/ha, de café beneficiado, das 17 colheitas realizadas, e as safras foram estatisticamente analisadas, divididas em cinco grupos: 1) média do biênio inicial (duas primeiras colheitas); 2) média do primeiro ciclo de podas (cinco safras - 3a à 7a colheita); 3) média do segundo ciclo de podas (cinco safras - 8 a à $12^{a}$ colheita); 4) média do terceiro ciclo de podas (cinco safras - 13a à 17a colheita) e 5) média das 17 safras.

Pela diversidade dos tratamentos, foram aplicados contrastes ortogonais nas comparações entre as médias dos tratamentos.

\section{RESULTADOS E DISCUSSÃO}

Na Tabela 2 é apresentado o resumo da análise de variância dos cinco períodos estudados. Os resultados dessa análise indicaram haver diferenças significativas entre as duas variedades no que diz respeito a sua produção. Os dados referentes à produtividade média das variedades estão relatados na Tabela 3. Os resultados mostram produções mais elevadas de 'Caturra' em relação à da 'Mundo Novo' nas duas primeiras safras. Essa maior produtividade foi causada não apenas pelas características das variedades, mas também pelo fato de a 'Mundo Novo' ter sido cultivada em densidade de plantio menor do que a 'Caturra'. Nessa fase jovem do cafeeiro, ainda não havia iniciado a concorrência entre plantas nos espaçamentos mais adensados, e nem os diversos problemas que o fechamento das lavouras ocasionam, além de não ter iniciado as podas regulares.

Observa-se, também, que com o envelhecimento das plantas ocorreu acentuada queda de produção na variedade Caturra, enquanto a Mundo Novo manteve o potencial produtivo até o final do período avaliado. Na média geral das 17 colheitas, os tratamentos com a 'Mundo Novo' apresentaram produtividade $100 \%$ superior à dos tratamentos com 'Caturra'.

Com a variedade Caturra, em todos os períodos estudados foram encontradas diferenças significativas entre os sistemas com densidades de $5 \mathrm{~m}^{2} /$ cova, conduzidos sem podas, e os sistemas com densidades de 3,2 e $1 \mathrm{~m}^{2} /$ cova, conduzidos com podas programadas (adensados). Na Tabela 4 estão apresentadas as médias de produtividade em função dos sistemas nos períodos estudados. Em ambos os sis-

TABELA 2. Análise de variância dos dados de produção (kg/ha) de café nos cinco períodos estudados.

\begin{tabular}{|c|c|c|c|c|c|c|}
\hline \multirow[t]{2}{*}{ Fonte de variação } & \multirow[t]{2}{*}{ GL } & \multicolumn{5}{|c|}{ Quadrado médio } \\
\hline & & Biênio inicial & $1^{\circ}$ ciclo & $2^{\underline{0}}$ ciclo & $3^{-0}$ ciclo & 17 safras \\
\hline Bloco & 3 & 217528 & 46300 & 18996 & 14755 & 32777 \\
\hline Tratamento & 9 & $251959 * *$ & $617687 * *$ & $4111136^{* *}$ & $1185772 * *$ & $502899 * *$ \\
\hline Mundo Novo vs Caturra & 1 & $1576147 * *$ & $4801507 * *$ & $297050 * *$ & $9593805^{* *}$ & $3680974 * *$ \\
\hline Dentro Caturra & 6 & $3151519 * *$ & $118050^{* *}$ & $10354 *$ & 18620 & $124666^{* *}$ \\
\hline $5 \mathrm{~m}^{2}$ vs $\left[3,2\right.$ e $\left.1 \mathrm{~m}^{2}\right]$ & 1 & $3608588 * *$ & $156022^{* *}$ & 188 & $766362 * *$ & $98002 * *$ \\
\hline Dentro 3,2 e $1 \mathrm{~m}^{2}$ & 5 & $3059985^{* *}$ & $105884 * *$ & $12387^{*}$ & 19553 & $129999 * *$ \\
\hline Espaçamento & 2 & $6697597 * *$ & $233430^{* *}$ & $29695^{* *}$ & $36913 *$ & $302368^{* *}$ \\
\hline Esp. linear & 1 & $13104400 * *$ & $459684^{* *}$ & $59049 * *$ & $70968^{* *}$ & $600718^{* *}$ \\
\hline Esp. quadrático & 1 & $290785^{*}$ & 7176 & 341 & 2858 & 4019 \\
\hline $\mathrm{N}^{\mathrm{o}}$ plantas/cova & 1 & $1505004^{* *}$ & 5104 & 2204 & 20556 & $44416 * *$ \\
\hline Esp. x $\mathrm{N}^{0}$ plantas/cova & 2 & $199868 *$ & 28713 & 171 & 1690 & 420 \\
\hline Dentro Mundo Novo & 2 & $1095836 * *$ & 24689 & $1670525^{* *}$ & $483211 * *$ & $48563 * *$ \\
\hline $6 \mathrm{~m}^{2}$ vs $3 \mathrm{~m}^{2}$ & 1 & $2170248 * *$ & 80 & $212816^{* *}$ & $963843^{* *}$ & $77173 * *$ \\
\hline Dentro $6 \mathrm{~m}^{2}$ & 1 & 21424 & 49298 & $3128234 * *$ & 2578 & 19953 \\
\hline Livre cresc. vs. Decotado & 1 & 21424 & 49298 & $3128234 * *$ & 2578 & 19953 \\
\hline Resíduo & 27 & 50727 & 15125 & 3569 & 9874 & 7190 \\
\hline
\end{tabular}


temas, houve pronunciada queda de produtividade ao longo dos períodos, porém esse decréscimo foi mais acentuado nos tratamentos em espaçamentos adensados com podas programadas, haja vista que no primeiro período (biênio inicial), os adensados apresentaram produções duas vezes superiores ao espaçamento largo $\left(5 \mathrm{~m}^{2}\right)$; no segundo período (primeiro ciclo de podas), a produção foi de apenas 1,24 vez superior; não diferiu significativamente no terceiro período (segundo ciclo de podas) e foi $1,34 \mathrm{vez}$ inferior no último período (terceiro ciclo de podas). Apesar de ser o decréscimo de produção mais acentuado nos espaçamentos adensados, tanto nas maiores densidades de plantio como no espaçamento largo houve elevada queda na produtividade entre o primeiro e o segundo ciclo, mostrando baixa viabilidade da produção de 'Caturra' após sete safras, nas condições da região.

Entre os espaçamentos adensados, referentes à variedade Caturra, formou-se um fatorial $3 \times 2$ entre os fatores: espaçamento, nos níveis de 3, 2 e $1 \mathrm{~m}^{2} /$ cova combinados com os níveis de uma e duas plantas por cova, que são os níveis mais adotados no Brasil. Dentre esses fatores, o espaçamento foi significativo em todos os períodos seguindo o modelo de regressão linear, em que a produção diminuiu com o aumento da área ocupada por cova, porém esse decréscimo diminui ao longo dos períodos, apresentando coeficientes angulares $\left(\beta_{1}\right)$ de: -905; -169,5; -60,75 e -66,6 no biênio inicial, e os ciclos de podas (primeiro, segundo e terceiro, respectivamente). Esses resultados permitem concluir que as diferenças de produção entre as três densidades estudadas diminui ao longo dos períodos estudados.

Com relação ao número de plantas por cova, houve diferenças significativas apenas no biênio inicial e na média das 17 safras; todavia, no biênio inicial, a interação entre a área ocupada por cova e o número de plantas na cova também apresentou diferenças significativas. O desdobramento do número de plantas por cova dentro dos espaçamentos é apresentado na Tabela 5, onde houve diferenças significativas nos espaçamentos de 1 e $2 \mathrm{~m}^{2} /$ cova. As produções médias são mostradas na Tabela 6 , onde se verifica ser o uso de duas plantas por cova superior ao uso de apenas uma planta. Neste caso, a decisão pela adoção de uma ou duas plantas por cova em plantios adensados merece ser regida à luz de critérios econômicos, com relação ao custo da implementação da lavoura e do retorno apresentado nas duas primeiras safras.

Como a média de produção do biênio inicial foi substancialmente superior à dos demais períodos, a média de produção nas 17 safras também resultou em diferenças significativas quanto ao número de plantas por cova; todavia, o aumento da produtividade na média geral com a adoção de duas plantas por cova em relação a uma planta foi menor do que no biênio inicial.

Esses resultados diferem dos encontrados por Henao \& Mestre (1988a), que concluíram haver diferenças de produção em função do número de plantas por cova em um mesmo espaçamento,

TABELA 3. Médias de produção de café (kg/ha/ano) em função da variedade, nos cinco períodos estudados.

\begin{tabular}{lccccc}
\hline Variedade & Biênio inicial & $1^{0}$ ciclo & $2^{\underline{0}}$ ciclo & $3^{\underline{0}}$ ciclo & 17 safras \\
\hline Mundo Novo & $1.430,83$ & $1.905,83$ & 849,33 & $1.264,1$ & $1.340,73$ \\
Caturra & $1.866,86$ & $1.149,79$ & 220,36 & 195,4 & 678,09 \\
\hline
\end{tabular}

TABELA4. Médias de produção de café (kg/ha/ano) da variedade Caturra em função do sistema com espaçamento largo e adensado.

\begin{tabular}{lccccc}
\hline Sistema & Biênio inicial & $1^{\underline{0}}$ ciclo & $2^{\underline{0}}$ ciclo & $3^{\underline{0}}$ ciclo & 17 safras \\
\hline $5 \mathrm{~m}^{2}$ livre crescimento & 987,50 & 954,00 & 214,00 & 250,4 & 533,18 \\
$3,2 \mathrm{e} 1 \mathrm{~m}^{2}$ podados BF & $2.013,42$ & $1.182,42$ & 221,42 & 186,4 & 702,24 \\
\hline
\end{tabular}


mas não são diferentes quando o número de plantas/ha for igual.

Em Mundo Novo, comparando-se o plantio adensado ( $3 \mathrm{~m}^{2} /$ cova) com o cultivo do cafeeiro em espaçamento largo ( $6 \mathrm{~m}^{2} /$ cova $)$, verificou-se não haver diferenças significativas apenas no primeiro ciclo de podas. As médias são mostradas na Tabela 7, onde mais uma vez fica evidente a maior produtividade do cafezal adensado nas primeiras safras. Entretanto, essa situação se inverte após as sete primeiras colheitas, sendo que a produtividade no espaçamento largo se mantém estabilizada, enquanto no plantio adensado a produção decresce ao longo dos períodos, mesmo adotando-se as podas programadas.

TABELA 5. Análise de variância dos dados de produção $(\mathrm{kg} / \mathrm{ha})$ para o desdobramento do número de plantas/cova nos espaçamentos estudados, no biênio inicial.

\begin{tabular}{lcc}
\hline Fonte de variacão & GL & Quadrado médio \\
\hline $\mathrm{N}^{\mathrm{o}}$ plantas/cova dentro de $3 \mathrm{~m}^{2}$ & 1 & 37264 \\
$\mathrm{~N}^{\mathrm{o}}$ plantas/cova dentro de $2 \mathrm{~m}^{2}$ & 1 & $880464 * *$ \\
$\mathrm{~N}^{\mathrm{o}}$ plantas/cova dentro de $1 \mathrm{~m}^{2}$ & 1 & $987012 * *$ \\
\hline
\end{tabular}

TABELA 6. Médias de produção de café (kg/ha/ano) da variedade Caturra, em função do número de plantas/cova e do espaçamento, no biênio inicial e na média das 17 colheitas.

\begin{tabular}{cccc}
\hline \multirow{2}{*}{$^{\mathrm{o}}$ de plantas/cova } & \multicolumn{2}{c}{ Biênio inicial } & \multirow{2}{*}{17 safras } \\
\cline { 2 - 3 } & $2 \mathrm{~m}^{2}$ & $1 \mathrm{~m}^{2}$ & \\
\hline 1 & $1.526,0$ & $2.645,0$ & 659,23 \\
2 & $2.189,5$ & $3.347,5$ & 745,26 \\
\hline
\end{tabular}

Quando foram usados espaçamentos largos na Mundo Novo, a adoção de poda tipo decote a $2 \mathrm{~m}$ de altura provocou diferenças consideradas significativas em relação ao livre crescimento (sem podas) apenas no segundo ciclo de podas, resultando em produções médias de 1.056,5 e 830,5 kg/ha de café beneficiado, nos cafeeiros a livre crescimento e nos decotados, respectivamente. Esse decréscimo na produtividade dos cafeeiros decotados pode ser atribuído à diminuição da área produtiva causada pela poda (decote) executada após a sétima safra. Como no período subsequiente (terceiro ciclo de podas) as produções não diferiram significativamente, concluise que a aplicação de poda do tipo decote provoca redução de produção apenas no ano seguinte à sua realização; contudo, ao adotar essa prática, deve-se levar em consideração que ela promove maior facilidade, e, conseqüentemente, maior rendimento da colheita, e em contrapartida necessita de desbrotas anuais para manter a altura das plantas.

Os resultados mostraram ser o uso de espaçamentos mais adensados, com a adoção de podas regulares no esquema Beaumont \& Fukunaga, mais vantajoso até a sétima safra, após a qual as produtividades não são satisfatórias. Tal fato leva a crer que tecnologias promissoras para a região possam ser utilizadas com a adoção de plantios em espaçamentos adensados, que permitam ser transformados em espaçamentos tradicionais, pela eliminação de ruas ou pelo uso de recepa total a períodos regulares de cinco a sete colheitas.

A variedade Caturra demonstrou-se menos vigorosa que a Mundo Novo nas condições da região, por apresentar queda de produtividade após sete safras, mesmo em espaçamentos largos. $\mathrm{O}$ uso de recepa total a períodos regulares talvez seja uma solução para esse problema de menor vigor da variedade Caturra.

TABELA 7. Média de produção de café (kg/ha/ano) da variedade Mundo Novo, em função do espaçamento, nos cinco períodos estudados.

\begin{tabular}{cccccc}
\hline Área/cova & Biênio inicial & $1^{{ }^{\circ}}$ ciclo & $2^{\circ}$ ciclo & $3^{\underline{0}}$ ciclo & 17 safras \\
\hline $6 \mathrm{~m}^{2}$ & $1.131,25$ & $1.904,0$ & 943,5 & $1.464,5$ & $1.397,44$ \\
$3 \mathrm{~m}^{2}$ & $2.031,00$ & $1.909,5$ & 661,0 & 863,3 & $1.227,32$ \\
\hline
\end{tabular}




\section{CONCLUSÕES}

1. O aumento da densidade de plantio propicia aumento de produção nas duas primeiras colheitas na variedade Mundo Novo.

2. O aumento da população de plantas propicia aumento de produção durante as sete primeiras colheitas na variedade Caturra.

3. O aumento da densidade de plantio é prejudicial à produção após doze e sete colheitas na 'Caturra' e na 'Mundo Novo', respectivamente.

4. A variedade Caturra apresenta acentuado decréscimo na produção após sete colheitas; a variedade Mundo Novo mantém o potencial produtivo.

5. A adoção de decote provoca diminuição na produção, no ciclo seguinte à sua realização, na variedade Mundo Novo.

\section{REFERÊNCIAS}

BEAUMONT, J.H.; FUKUNAGA, E.T. Factors affecting the growth and yield of coffee in Kona, Hawaii. Honolulu: University of Hawaii, 1958. 39p. (Hawaii Agricultural Experiment Station. Bulletin 113).

BELLAVITA, O. Rentabilidad de la exploración del café al sol. Agronomia Tropical, Maracay, v.18, n.2, p.283 292,1968 .

HANGDONG, A.S.; BARTOLOME, R. A progress report on the effect of spacing on the yield of arabica coffee. Coffee and Cacao Journal, Manila, v.6, n.3, p.53-55, 1963.

HANGDONG, A.S.; BARTOLOME, R. The effect of the spacing on the yield of arabica coffee. Coffee and Cacao Journal, Manila, v.9, n.1, p.10-18, 1966.

HENAO, A.V.; MESTRE, A.M. Efecto de la densidad de población y de la disposición de los árboles en la producción de café. Cenicafé, Caldas, v.39, n.2, p.3142, 1988a.

HENAO, A.V.; MESTRE, A.M. Efecto de la distancia de siembra y del número de plantas por hoyo sobre la producción de café (Coffea arabica $\mathrm{L}$. var. Caturra). Cenicafé, Caldas, v.39, n.1, p.15-27, 1988b.

LEON, J.L.; UMAÑA, R. Rendimiento de café en setos comparado con sistema a siembra corriente. Turrialba, Turrialba, Costa Rica, v.9, n.2, p.4350, 1959.

Pesq. agropec. bras., Brasília, v.34, n.8, p.1379-1384, ago. 1999
MITCHELL, H.W. Research on close spacing for intensive coffee production in Kenya. Kenya Coffee, Nairobi, v.41, n.481, p.124-137, 1976.

OLIVEIRA, J.A.; MATIELLO, J.B.; MIGUEL, A.E Curvas de produção de cafeeiros Catuaí em ensaio de espaçamentos progressivos na zona da mata de Minas Gerais. In: CONGRESSO BRASILEIRO DE PESQUISAS CAFEEIRA, 16., 1990, Espírito Santo do Pinhal - SP. Resumos... Rio de Janeiro: IBC, 1990. p.32-34.

PAVAN, M.A.; CHAVES, J.C.D.; ANDROCIOLI FILHO, A. Produção de café em função da densidade de plantio, adubação e tratamento fitossanitário. Turrialba, Turrialba, v.44, n.4, p.227-231, 1994.

PERES, S.V.M. Veintecinco años de investigación sistemática del cultivo del café en Costa Rica: 1950-1975. Agronomía Costaricense, San José, v.1, n.2, p.169185, 1977.

RODRIGUEZ, S.J.; BOSQUE, L.; PEREZ, P.R.; MORALES, M.A. Effect of planting distances on schaded coffee yield in Puerto Rico. The Journal of Agriculture of the University of Puerto Rico, Río Piedras, v.50, n.2, p.82-86, 1966.

SCARANARI, H.J.; NOGUEIRA NETO, P. Efeito da densidade de plantio sobre a produção de café 'Mundo Novo'. Bragantia, Campinas, v.22, n.1, p.373382,1963 .

SIQUEIRA, R.; ANDROCIOLI FILHO, A.; CARAMORI, P.H.; PAVAN, M.A. Espaçamento e produtividade do cafeeiro. Londrina: IAPAR, 1985. 6p. (IAPAR. Informe de Pesquisa, 56).

TOLEDO, A.R.; MIGUEL, A.E.; MATIELLO, J.B. Combinação de densidades de plantio com sistemas de podas no cultivo de MN-Acaiá, em Varginha-MG. In: CONGRESSO BRASILEIRO DE PESQUISA CAFEEIRA, 20., Guarapari - ES. Resumos...Rio de Janeiro. IBC. 1994. p.112-115.

VIANA, A.S.; CAMARGO, A.P.; DIAS, H.S. Efeito de espaçamentos progressivos na produção de café por cova e por área. In: CONGRESSO BRASILEIRO DE PESQUISA CAFEEIRA, 6., Ribeirão Preto SP. 1978. Resumos...Rio de Janeiro: IBC, 1978. p.10-12. 